1

\title{
Ten-Year time trends in mental and physical health correlates of weight/shape overvaluation
}

Short running title:

Trends in weight/shape overvaluation

\section{Authors and Affiliations}

Danilo Dias Santana ${ }^{1,2, *}$, Deborah Mitchison ${ }^{2,3}$, Scott Griffiths ${ }^{4}$, Jose Carlos Appolinario ${ }^{5}$, Gloria Valeria da Veiga ${ }^{1}$, Stephen Touyz $^{6}$, Phillipa Hay ${ }^{7}$

${ }^{1}$ Josué de Castro Institute of Nutrition, Federal University of Rio de Janeiro, Rio de Janeiro, Brazil

${ }^{2}$ School of Medicine, Western Sydney University, New South Wales, Australia

${ }^{3}$ Centre for Emotional Health, Department of Psychology, Macquarie University, New South Wales, Australia

${ }^{4}$ Melbourne School of Psychological Sciences, University of Melbourne, Victoria, Australia

${ }^{5}$ Group of Obesity and Eating Disorders, Institute of Psychiatry, Federal University of Rio de Janeiro, Rio de Janeiro, Brazil

${ }^{6}$ School of Psychology, University of Sydney, New South Wales, Australia

${ }^{7}$ Translational Health Research Institute, School of Medicine, Western Sydney University, New South Wales, Australia

*Corresponding author: mobile - +55 (21) 990867254, email - dias.danilo@ hotmail.com

\section{Conflict of Interest statement}

Dr Scott Griffiths is a member of the executive board of the Australian and New Zealand Academy for Eating Disorders (2017-) and has received research grants from the NHMRC.

Professor Jose Carlos Appolinario receives/has received research grants, consultancy fees, and advisory board fees from Shire Pharmaceuticals. He has prepared also an Educational Material about Binge Eating Disorder for Shire Pharmaceuticals. He receives/has received royalties/honoraria from Artmed Panamericana Editora. He also received a research grant from the Brazilian National Research Council (CNPq).

Professor Gloria Valeria da Veiga received a research grant from the Brazilian National Research Council (CNPq).

Professor Stephen Touyz receives royalties/honoraria from Hogrefe and Huber, McGraw Hill Educational and Biomed Central and has received research grant funding from the NHMRC, ARC and Shire Pharmaceuticals. He has also received an honorarium from Sheppard Pratt. He is the Chair of the Shire BED Australian Advisory Committee on Binge Eating Disorder and has

This is the author manuscript accepted for publication and has undergone full peer review but has not been through the copyediting, typesetting, pagination and proofreading process, which may lead to differences between this version and the Version of Record. Please cite this article as doi: $10.1002 /$ erv.2672

This article is protected by copyright. All rights reserved. 
received honoraria/ consulting fees and travel grant funding as well. He is a mental health adviser to the Commonwealth Department of Veteran Affairs.

Professor Phillipa Hay receives/has received sessional fees and lecture fees from the Australian Medical Council, Therapeutic Guidelines publication, and New South Wales Institute of Psychiatry and royalties/honoraria from Hogrefe and Huber, McGraw Hill Education, and Blackwell Scientific Publications, Biomed Central and Plos Medicine and she has received research grants from the NHMRC and ARC. She is Deputy Chair of the National Eating Disorders Collaboration Steering Committee in Australia (2012) and Member of the ICD-11 Working Group for Eating Disorders (2012-) and was Chair Clinical Practice Guidelines Project Working Group (Eating Disorders) of RANZCP (2012-2015). She has prepared a report under contract for Shire Pharmaceuticals in regards to Binge Eating Disorder (July 2017).

The other authors declare no conflicts of interest.

\section{Funding}

Funding for the eating disorder questions in the surveys was received from internal James Cook and Western Sydney University grants to Professor Phillipa Hay; University of Sydney internal research funds of Professor Stephen Touyz; and Dr Scott Griffiths is funded by an NHMRC Early Career Fellowship (grant number: 1121538). 
This article is protected by copyright. All rights reserved. 


\title{
Ten-Year time trends in mental and physical health correlates of weight/shape overvaluation
}

\begin{abstract}
Objective: To investigate the relationships between weight/shape overvaluation, health-related quality of life (HRQoL) and functional role impairment (days out of role; DOR) in the general population over 11 years. Method: Five cross-sectional surveys of men and women representative of the South Australian population were conducted in 2005, 2008, 2009, 2015, and 2016 ( $n$ total $=$ 15,140). Data were collected on demographics, overvaluation, HRQoL, DOR, and eating disorder behaviors. Results: Between 2005 and 2016, the prevalence of moderate overvaluation increased from $18.1 \%$ to $40.0 \%$, marked overvaluation from $7.5 \%$ to $23.7 \%$, and extreme overvaluation from $3.1 \%$ to $9.2 \%$ (all $p<.001$ ). Overvaluation at any level was associated with more DOR in 2005 but not in 2016, and the association between HRQoL impairment and overvaluation weakened over time. Conclusion: While the population prevalence of overvaluation has increased significantly in the past decade, the impairment associated with it appears to have reduced.
\end{abstract}

\section{Highlights:}

The Australian community prevalence of all levels of weight/shape overvaluation has increased significantly since 2005 .

Associations between days out of role, health-related quality of life impairment and overvaluation has weakened over time.

Levels of comorbid obesity, binge eating and strict dieting increased among participants with overvaluation.

Keywords: weight/shape overvaluation, health related quality of life, role impairment, eating disorder behaviors, epidemiology. 


\section{Introduction}

Eating disorders are characterized by disturbances of eating behaviors and a core psychopathology centered on food, eating and body image concerns (American Psychiatric Association, 2013). According to the fifth edition of the Diagnostic and Statistical Manual of Mental Disorders (DSM-5) (American Psychiatric Association, 2013), there are four main types of eating disorders: anorexia nervosa, bulimia nervosa, binge eating disorder (BED), and also other specified or unspecified feeding or eating disorders (OS/UFED). Excessive influence of weight and/or shape on self-evaluation, referred to as overvaluation (Hrabosky, Masheb, White, \& Grilo, 2007; Mitchison et al., 2017) is considered a central feature across all eating disorders (Fairburn, Cooper, \& Shafran, 2003) and is a core criterion for anorexia nervosa and bulimia nervosa. However, it may also occur in people with BED and OS/UFED (American Psychiatric Association, 2013). For example, Grilo et al. (2008) noted that $56 \%$ of participants with BED in this study were categorized as having weight/shape overvaluation. Furthermore, BED participants with overvaluation reported greater eating-related psychopathology and depression levels than those without overvaluation. A later study found that overvaluation was a risk factor for binge eating onset and was associated with subjective social status impairment in adolescents who were overweight and who were binge eating (Sonneville et al., 2015). Linardon (2016) in a recent metaanalysis reported consistent relationships between overvaluation and impairments in psychological functioning in people with BED and bulimia nervosa.

Previous Australian community prevalence estimates of overvaluation are around $14 \%$ in men and $23 \%$ in women (Mitchison, Mond, Slewa-Younan, \& Hay, 2013). Importantly, overvaluation has been found to be associated with significant impairment in health related quality of life (HRQoL) (Mitchison, Hay, Slewa-Younan, \& Mond, 2012) and reduced productivity (Mond \& Hay, 2007), as indicated by scores on widely-used measures such as the health outcome measure short-form scales (SF-36 and SF-12) (Ware, Kosinski, \& Keller, 1994; Ware, Kosinski, \& Keller, 
1996) and the National Comorbidity Replication Survey days out of role question (Hudson, Hiripi, Pope, \& Kessler, 2007). In addition, overvaluation may be associated with general psychopathology such as low self-esteem and eating disorders severity (Gianini et al., 2017; Lydecker, White, \& Grilo, 2017). In a community-based study of men and women, Mond \& Hay (2007) reported that participants who had disordered eating behaviors as well as overvaluation reported a higher number of days out of role (be unable to work, study or complete household responsibilities because of physical or emotional health problems) compared to participants with eating disorder behaviors but no overvaluation. There is mixed evidence for gender differences in the impact of overvaluation on health. For instance, in population-based studies, Mitchison et al. (2013) found that overvaluation had a greater impact on the mental HRQoL (Ware, Kosinski, \& Keller, 1994) of adult women compared to men, but among adolescents (Mitchison et al., 2017) was more consistently associated with other eating disorder behaviors and psychological distress in boys compared to girls.

While previous population-based studies have assessed the changing prevalence of eating disorder behaviors (Da Luz et al., 2017; Mitchison, Touyz, González-Chica, Stocks, \& Hay, 2017), and their comorbidity with obesity, no study as far as we are aware has examined point prevalence changes in weight/shape overvaluation over time. This is an important question to pursue however, given the centrality of overvaluation to the diagnostic models of eating disorders, and thus the implications for the population burden of eating disorder problems. In regards to time trends in the prevalence of eating disorder behaviors, Da Luz et al. (2017) have recently observed that the prevalence of obesity, eating disorder behaviors, and their comorbid occurrence increased significantly in the population from 1995 to 2015. The highest rate of increase observed was for the prevalence of obesity with comorbid binge eating (7.3-fold) and obesity with comorbid extreme dieting (11.5-fold). On the other hand, Mitchison, Touyz, González-Chica, Stocks, \& Hay (2017) found that while binge eating prevalence had increased in the population between 1998 and 2015, its relationship with HRQoL impairment and days out of role had weakened. This paper suggests that as the prevalence in binge eating increased, it may have become more socially acceptable and thus be less likely to be associated with either distress or impairment. However, they also point out that there is a core and relatively stable group who remain distressed and impaired by binge eating, and these people are also more likely to engage in more frequent binge eating. Whether or not the 
relationship between overvaluation and indicators of impairment has changed over time remains unknown.

Therefore, the aim of this research was to investigate the relationships between overvaluation with HRQoL and role impairment (days out of role) over time, using consecutive cross-sectional population-based samples of Australian men and women, surveyed between 2005 and 2016. A secondary aim was to assess changes over time in the relationship between overvaluation and disordered eating behaviors and obesity. Given the documented increases in prevalence of disordered eating behaviors over time, it was hypothesized that the prevalence of overvaluation will have increased between 2005 and 2016.

\section{Methods}

\section{Sampling procedures}

The data included in this study were sourced from sequential cross-sectional Health Omnibus Surveys, which are conducted annually by Harrison Health Research under the auspices of the South Australian Health Commission. Researchers pay to include items in the survey. It comprises face-to-face interviews of a representative sample of the adult population in South Australia (Taylor, Dal Grande, \& Wilson, 2006). Five surveys that assessed overvaluation were conducted in the years 2005, 2008, 2009, 2015 and 2016. For the purpose of this study, data from 2008/2009 and 2015/2016 were pooled so that three periods were compared: 2005, 2008/9, 2015/6.

In each survey year, metropolitan and rural 'collector districts' were selected based on a probability proportional to size sampling procedure according to the latest Australian Bureau of Statistics Census data. Ten houses within each district were chosen to conduct interviews in. The resident who had their birthday most recently and who was 15 years or older was interviewed. Up to six visits were made to each household. The samples were non-replacement. Pilot testing was conducted to ensure participant understanding and feasibility of the questions. Rates of response for each year were $63.1 \%(n=3047)$ in $2005,62.8 \%(n=3034)$ in $2008,59.3 \%(n=3007)$ in 2009 , $57.3 \%(n=3005)$ in 2015 , and 58.4\% $(n=3047)$ in 2016. The most common reason for not participating was refusal. Participation rates of eligible household members were higher: e.g. $66.1 \%$ in 2015 and $68 \%$ in 2016. 
Ethics

Adult participants provided verbal rather than written informed consent, due to the practicalities of carrying out a large-scale survey and the low risk nature of the survey content. For minors (15-17 year olds) enrolled in the study, written consent was obtained from the participant's parent/guardian. The 2005-2009 surveys were approved by the research ethics committee of the Government of South Australia, Department of Health, and the 2015-2016 surveys were approved by the University of Adelaide Human Research Ethics Committee.

\section{Measures}

Demographic information and body mass index. Demographic information collected included gender, age and highest educational attainment. Participants were also asked their height and weight, from which BMIs $\left(\mathrm{kg} / \mathrm{m}^{2}\right)$ were calculated and were classified according to the World Health Organization (1998) criteria: underweight $=$ BMI $<18.5$, healthy weight $=18.5 \leq$ BMI < 25.0, overweight $=25.0 \leq \mathrm{BMI}<30.0$, and obese $=\mathrm{BMI} \geq 30.0$. For adolescents the following categories were used: low weight $(\mathrm{Z}$-score $<-2)$; adequate weight $(\mathrm{Z}$-score $\geq-2$ and $\leq 1)$; overweight (Z-score $>1$ and $\leq 2$ ) and obesity (Z-score $>2$ ) (Onis et al., 2007).

Weight/shape overvaluation. This was measured by having participants rate the importance they placed on weight or shape in determining their self-evaluation, from 0 (no importance) to 6 (extreme importance). A score of 4 or more was used to indicate the presence of moderate weight/shape overvaluation, 5 or more for marked overvaluation, and 6 for extreme weight/shape overvaluation. The question used was 'On a scale of 0-6, where 0 is not at all important and 6 is extremely or the most important issue. How important an issue has your weight and/or your shape been to how you think about (judge or view) yourself as a person in the past three months? (It has been a really important issue to them, their self-esteem or their self-confidence'), based on diagnostic questions obtained from the Eating Disorder Examination (EDE) (Fairburn \& Cooper, 1993).

Disordered eating behaviors. Questions to ascertain the presence of these behaviors were based on the EDE (Fairburn \& Cooper, 1993), a structured interview used for eating disorder diagnosis. Participants were asked whether they regularly (at least once per week over the past three 
months) engaged in (a) objective binge eating (eating an objectively large amount of food with a sense of loss of control), (b) extreme dieting (going on a very strict diet or fasting to control weight or shape), and (c) purging (use of laxatives, diuretics, or self-induced vomiting to control weight or shape). The specific wording of the questions about these behaviors has been previously published (Hay, Mond, Buttner, \& Darby, 2008).

Health-related quality of life. The Medical Outcomes Study Short Form questionnaires were administered by the interviewers in the 2008 (SF-36) and 2015/6 (SF-12) surveys. These questionnaires measure health-related quality of life, and yield physical health (PCS) and mental health (MCS) component summary scores. Items assess impairment in physical and emotional health and the extent to which health status has limited quality of life in various domains (e.g., occupational, social, and other roles). The scales are the most widely used measure of health-related quality of life. Scores are transformed into T-scores, with a mean value of 50 and standard deviation of 10, and higher scores indicate greater quality of life. Previous reports support direct comparison of PCS and MCS scores on the longer (SF-36) vs. shorter (SF-12) scales (e.g. Müller-Nordhorn, Roll, \& Willich, 2004; Lacson et al. 2010).

Days out of role. Functional health impairment was assessed in the 2005, 2009 and 2016 surveys with a single question modeled on the days-out-of-role questions employed in the National Comorbidity Study (Kessler \& Frank, 1997). Specifically, participants were asked: 'During the past 4 weeks, on how many days, if any, were you unable to complete your work, study or household responsibilities because of any problem with your (physical or emotional) health?' A response between 0 (no days) and 28 (every day) was required. Previous research has indicated convergent validity of this item with the MCS and PCS subscales of the SF-12, demonstrated by correlations of moderate strength $(r=0.40-0.50)$ (Mond, Hay, Rodgers, \& Owen, 2007). Hence, the measure appears to be sensitive to both physical and mental health limitations.

\section{Data analysis}

Data from each survey were weighted based on the correspondent sampling process and reweighted to the population distribution in the most proximal Australian Census to the survey (e.g., 2006 Census for the 2008 survey). All analyses were performed using SPSS (v.24). Descriptive 
statistics were generated for all demographic variables and chi-square $\left(\chi^{2}\right)$ tests (for categorical variables: gender and highest educational attainment) or ANOVAs (for continuous variables: age and $\mathrm{BMI}$ ) were employed to compare differences between survey years.

$\chi^{2}$ tests and multivariate binary logistic regressions were employed to assess the prevalence of the three levels of overvaluation and differences in the likelihood (odds ratios) of reported levels of overvaluation between survey years (2005, 2008/9, 2015/6). A significant positive skew was observed for the days out of role variable (Kolmogrov-Smirnov $=0.409, p<0.001$ ). Thus, nine Mann-Whitney tests were conducted to compare days out of role between participants who scored above versus below each overvaluation level within the three survey years that collected these data: 2005, 2009, and 2016.

$\chi^{2}$ tests and multivariate binary logistic regressions were employed to test whether the likelihood of obesity and eating disorder behaviors (objective binge eating, strict dieting/fasting, purging) among people with varying levels of overvaluation differed across survey years. In each one of these regressions, the main effects and interaction between overvaluation and survey year was assessed.

Finally, three MANCOVAs were employed for each level of overvaluation, with PCS and MCS scores as the dependent variables, and survey year (2008, 2015/6) and overvaluation as the independent variables, in order to assess change over time in the relationship between overvaluation and health-related quality of life. Bonferroni-adjusted post-hoc tests were run following each MANCOVA.

Covariates entered in the regressions in this study included age, gender, BMI (except in analyses examining obesity), and educational attainment. Missing data were observed within each survey year in regards to BMI, as not all participants disclosed self-reported weight and height. Missingness of this data ranged from $7.7 \%$ in $2005,10.1 \%$ in $2008 / 9$, to $8.8 \%$ in $2015 / 6$. Results were considered significant at $p<0.05$.

\section{Results}

In relation to changes in the sociodemographic features over time, mean age and BMI increased from the 2005 to the 2016 survey $(p<.001)$. The educational level of participants also 
increased significantly between 2005 and $2016(p<.001)$. Around 51\% of participants in all surveys were women (Table 1).

\section{Prevalence of Overvaluation: 2005 - 2016}

Table 2 displays the three-month prevalence rates of scoring moderate $(\geq 4)$, marked $(\geq 5)$, and extreme (=6) on weight/shape overvaluation. Moderate overvaluation increased from $18.1 \%$ to $40.0 \%$, marked from $7.5 \%$ to $23.7 \%$ and extreme overvaluation from $3.1 \%$ to $9.2 \%$, between 2005 and 2016. The three $\chi^{2}$ analyses comparing the prevalence of each of the three levels of overvaluation over the survey years were all significant (moderate overvaluation: $\chi^{2}(2)=454.49, p$ $<.001$; marked overvaluation: $\chi^{2}(2)=352.99, p<.001$; extreme overvaluation: $\chi^{2}(2)=114.69, p<$ .001 ), with a trend for the prevalence of each level of overvaluation to increase from 2005 to 2016. Logistic regressions revealed that relative to the 2005 survey, the odds of scoring moderate, marked, or extreme on overvaluation were significantly higher in both the 2008/9 survey and the 2015-6 survey. As can be seen in Table 2, these odds ratios tended to be higher in 2015/6 compared to $2008 / 9$.

\section{Days Out of Role: 2005 - 2016}

Table 3 displays the median number of days out of role in the past month and the results of the Mann-Whitney tests comparing participants who scored above and below each level of overvaluation. As can be seen, participants who scored above each cut-point for overvaluation reported a greater number of days out of role than participants who scored below the cut-point in 2005. In 2009, participants with marked or extreme overvaluation continued to report a greater number of days out of role, however this did not occur between participants with moderate overvaluation. Finally, in 2016, participants with overvaluation, at any level, were no more likely to report days out of role than participants who scored below these cut-offs.

\section{Health-Related Quality of Life: 2008 - 2016}

Table 4 presents the descriptive statistics for MCS and PCS scores. Controlling for the effects of BMI, age, gender, and educational attainment, and relative to participants without weight/shape overvaluation, overvaluation at any level was associated with lower MCS scores (all $p$ 
$<0.001$; partial $\left.\eta^{2}=.004-.007\right)$. Further moderate overvaluation $\left(p=0.005\right.$; partial $\left.\eta^{2}=.001\right)$ and extreme overvaluation $\left(p=0.020\right.$; partial $\left.\eta^{2}=.001\right)$ were also associated with higher and lower PCS scores, respectively. A significant interaction between survey year and overvaluation on MCS (but not on PCS) scores was observed at each level of overvaluation. Post-hoc tests within each survey year revealed that while overvaluation at any level was associated with lower MCS scores in $2008\left(p<0.001\right.$, partial $\eta^{2}=.007 ; p<0.001$, partial $\eta^{2}=.022 ; p<0.001 ;$ partial $\left.\eta^{2}=.020\right)$, marked overvaluation $(p=0.589)$ and extreme overvaluation $(p=0.600)$ were not associated with lower MCS scores in 2015/2016. On the other hand, moderate overvaluation did remain associated with significantly lower MCS scores in 2015/6 ( $p=0.004$; partial $\left.\eta^{2}=.003\right)$. When considering only those participants who reported moderate, marked, or extreme overvaluation, participants in 2008 always scored lower on the MCS than participants in 2015/6 (all $p<0.001$, partial $\eta^{2}=0.042-$ 0.117).

\section{Comorbid Weight and Eating Problems: 2005 - 2016}

Table 5 displays the prevalence of comorbidity of weight and eating disorder behaviors with overvaluation.

\section{Obesity}

Controlling for the effects of age, gender, and educational attainment, the odds of comorbid obesity with moderate overvaluation were significantly greater in 2008/9 (OR = 1.56) and 2015/6 $(\mathrm{OR}=2.12)$, relative to 2005 . The odds of comorbid obesity with marked and extreme overvaluation were also significantly greater in 2008/9 (marked: $O R=1.84$; extreme: $O R=2.12$ ) and 2015/6 (marked: $\mathrm{OR}=2.67$; extreme: $\mathrm{OR}=2.27$ ), relative to 2005. Full parameter estimates for all comorbidity regression analyses are available upon request.

\section{Objective Binge Eating}

Controlling for the effects of age, gender, educational attainment, and BMI, the odds of comorbid objective binge eating with moderate overvaluation were not significantly greater in $2008 / 9$, but were in 2015/6 (OR $=2.51$ ), relative to 2005. Similarly, the odds of comorbid objective binge eating with marked overvaluation and extreme overvaluation were also not significantly 
greater in 2008/9, but were in 2015/6 (marked overvaluation: OR $=2.73$; extreme overvaluation: OR $=1.92$ ), relative to 2005 .

\section{Strict Dieting/Fasting}

Controlling for the effects of age, gender, educational attainment, and BMI, the odds of comorbid strict dieting/fasting with moderate overvaluation were not significantly greater in 2008/9, but were in 2015/6 (OR $=1.44)$, relative to 2005. The odds of comorbid strict dieting/fasting with marked overvaluation were significantly greater in both $2008 / 9(\mathrm{OR}=1.50)$ and $2015 / 6(\mathrm{OR}=$ 1.53). On the other hand, the odds of comorbidity with extreme overvaluation was only significantly greater in 2008/9 $(\mathrm{OR}=1.63)$.

\section{Purging}

Controlling for demographic and BMI effects, the odds of comorbid purging with moderate overvaluation were not significantly greater in 2008/9, and were significantly lower in 2015/6 (OR $=0.50$ ), relative to 2005 . No differences in the likelihood of reported comorbid purging with either marked or extreme overvaluation were found in 2008/9 or 2015/6, relative to 2005 .

\section{Discussion}

In this paper, was found that the general population prevalence of moderate weight/shape overvaluation increased significantly (18.1\% to 40.0\%) between 2005 and 2016. Marked (7.5\% to $23.7 \%$ ) and extreme weight/shape overvaluation (3.1\% to 9.2\%) also increased between 2005 and 2016, suggesting that considering weight and shape to be central to one's self-evaluation is becoming very common. Another study with a general population sample of adults from Australia have reported a marked overvaluation prevalence of 10.8\% (Bentley, Mond, \& Rodgers, 2014) and Lydecker, White, \& Grilo (2017) observed a moderate overvaluation prevalence of $65.2 \%$ in a treatment-seeking patients group with BED.

In relation to role impairment in 2005, all levels of weight/shape overvaluation were associated with more days out of role, while in 2016 these associations did not appear. The relationship between HRQoL impairment, particularly mental health-related impairment, also 
changed over time. In 2008, participants at any level of overvaluation presented lower MCS scores when compared to people without overvaluation, whereas in 2015/6 only moderate overvaluation was associated with a poorer quality of life.

These findings of increased frequency in the context of decreased impairment support a suggestion of the "normalization" of weight/shape overvaluation. Steinglass \& Devlin (2017) in their commentary on the substantial increase of binge eating prevalence and decrease of disability around eating (Mitchison, Touyz González-Chica, Stocks, \& Hay, 2017) highlight the issue of how as population frequency of binge eating increases, it is tempting to think of the behavior as more normative. Furthermore, it is worth mentioning that the BMI in the community in Australia has also increased such that a high BMI (over $25 \mathrm{~kg} / \mathrm{m}^{2}$ ) is also now "normative". Understanding of the nosology and natural history of eating disorders in the population level (O'Connor, 1990) is informed by such normative data. Taken together, these findings suggest that that classification schemes in the future may need to adjust or reconsider severity thresholds for such psychopathology in eating disorders.

Other cultural or demographic aspects, such as changes in peer or media influences, reported in association with body dissatisfaction in adolescent girls (Rodgers, McLean, Marques, Dunstan, \& Paxton, 2016), could be influencing body image and impacting indirectly in this trend. However, overvaluation has not yet been widely studied in regards to these wider cultural influences and more research is needed.

It is also worth noting that unlike other body image constructs, impairment is not embedded in the operationalization of overvaluation. Overvaluation is the extent to which someone places a high level of importance of weight/shape on how they judge their own self-worth. In contrast, other body image constructs such as dissatisfaction with weight/shape are operationalized by distress (the extent to which one is unhappy with their weight/shape), and thus it may be expected that these may remain associated with indicators of impairment.

The present paper also found that the community prevalence of comorbid obesity and weight/shape overvaluation has increased significantly since 2005 for all levels of overvaluation. Furthermore, comorbid objective binge eating with weight/shape overvaluation increased just in the last 6 years (between 2008/9 and 2015/6). Comorbid strict dieting/fasting with weight/shape overvaluation increased significantly, between 2005 and 2008/9, for marked and extreme 
overvaluation and, in the last 6 years, for moderate and marked overvaluation. Da Luz et al. (2017) observed that the prevalence of obesity with comorbid binge eating and strict dieting/fasting, factors related to eating disorders issues, also increased significantly from 1995 to 2015. The results support a continuous increase of co-morbid eating disorder symptoms in people living with a larger body weight in the Australian population.

Strengths of this study include the use of large community-based samples, a selection of participants of both sexes, a wide range of age groups and wide (10-year) time frame. A central limitation of our study is that there is no dedicated instrument for measuring overvaluation. Further, the sensitivity of this item to sex differences in body overvaluation has not been confirmed, and this is notable because much recent research has focused on measurement sensitivity (or lack thereof) to these sex differences, including the EDE, from which the overvaluation items were obtained. An important direction for future research will be the development of standardized measures of weight/shape overvaluation, given their theoretical prominence and clinical significance as supported by the results of several studies.

A further limitation is the decreasing response rate over time. However, there were similar demographic profile across all surveys and changes were in accordance with wider secular trends in the Australian population (Australian Bureau of Statistics, 2017). Another limitation was that the same cohort was not assessed at each survey year, which would be important in confirming changes in overvaluation over time within individuals, as opposed to within populations. Other limitations included the lack of consistent assessment of health-related quality of life in only two of the three survey periods, small numbers of participants with purging, and self-report weight and height. One last limitation is that it was not possible account for the variance in days out of role attributed to mental health symptoms as opposed to weight/shape overvaluation because data on comorbid mental health symptoms were not available in this study.

In conclusion, all weight/shape overvaluation levels and the prevalence of comorbid obesity and overvaluation increased significantly in the last years. However, this growth has not been associated with a reduced quality of life over the years, which may indicate the "normalization" of overvaluation in the general population.

\section{References}


American Psychiatric Association (2013). Diagnostic and Statistical Manual of Mental Disorders: DSM-5 (5th ed.). Arlington, VA: American Psychiatric Publishing Inc.

Australian Bureau of Statistics (2017). Education and Work, Australia. Retrieved from https://www.abs.gov.au/ausstats/abs@.nsf/mf/6227.0

Bentley, C., Mond, J., \& Rodgers, B. (2014). Sex differences in psychosocial impairment associated with eating-disordered behaviour: What if there aren't any? Eating Behaviors, 15, 609-614. https://doi.org/10.1016/j.eatbeh.2014.08.015

Da Luz, F. Q., Sainsbury, A., Mannan, H., Touyz, S., Mitchison, D., \& Hay, P. (2017). Prevalence of obesity and comorbid eating disorder behaviors in South Australia from 1995 to 2015. International Journal of Obesity, 41, 1148-1153. https://doi.org/10.1038/ijo.2017.79

Fairburn, C. G., \& Cooper, Z. (1993). The eating disorder examination. In C. G. Fairburn \& G. Wilson (Eds.) (12th ed.). Binge Eating: Nature, Assessment and Treatment. New York, NY: Guildford Press.

Fairburn, C. G., Cooper, Z., \& Shafran, R. (2003). Cognitive behaviour therapy for eating disorders: A "transdiagnostic" theory and treatment. Behaviour research and therapy, 41, 509-528. https://doi.org/10.1016/S0005-7967(02)00088-8

Gianini, L., Roberto, C. A., Attia, E., Walsh, B. T., Thomas, J. J., Eddy, K. T., ... Sysko, R. (2017). Mild, moderate, meaningful? Examining the psychological and functioning correlates of DSM-5 eating disorder severity specifiers. International Journal of Eating Disorders, 50, 906-916. https://doi.org/10.1002/eat.22728

Grilo, C. M., Hrabosky, J. I., White, M. A., Allison, K. C., Stunkard, A. J., \& Masheb, R. M. (2008). Overvaluation of shape and weight in binge eating disorder and overweight controls: Refinement of a diagnostic construct. Journal of Abnormal Psychology, 117, 414-419. https://doi.org/10.1037/0021-843X.117.2.414

Hay, P. J., Mond, J., Buttner, P., \& Darby, A. (2008). Eating disorder behaviors are increasing: findings from two sequential community surveys in South Australia. PLoS One, 3, e1541. https://doi.org/10.1371/journal.pone.0001541

Hrabosky, J. I., Masheb, R. M., White, M. A., \& Grilo, C.M. (2007). Overvaluation of shape and weight in binge eating disorder. Journal of Consulting and Clinical Psychology, 75, 175-180. https://doi.org/10.1037/0022-006X.75.1.175

Hudson, J. I., Hiripi, E., Pope Jr, H. G., \& Kessler, R. C. (2007). The prevalence and correlates of eating disorders in the National Comorbidity Survey Replication. Biological psychiatry, 61, 348358. https://doi.org/10.1016/j.biopsych.2006.03.040

Kessler, R. C., \& Frank, R. G. (1997). The impact of psychiatric disorders on work loss days. Psychological Medicine, 27, 861-873.

Lacson, E., Xu, J., Lin, S. F., Dean, S. G., Lazarus, J. M., \& Hakim, R.M. (2010). A comparison of SF-36 and SF-12 composite scores and subsequent hospitalization and mortality risks in long-term dialysis patients. Clinical Journal of the American Society of Nephrology, 5, 252-260.

https://doi.org/10.2215/CJN.07231009 
Linardon, J. (2016). Correlates of the over-evaluation of weight and shape in binge eating disorder and mixed eating disorder samples: A meta-analytic review. Eating Disorders, 25, 183-198. https://doi.org/10.1080/10640266.2016.1260374

Lydecker, J.A., White, M.A., \& Grilo C.M. (2017). Form and formulation: Examining the distinctiveness of body image constructs in treatment-seeking patients with binge-eating disorder. Journal of Consulting and Clinical Psychology, 85, 1095-1103. https://doi.org/10.1037/ccp0000258

Mitchison, D., Hay, P., Griffiths, S., Murray, S. B., Bentley, C., Gratwick-Sarll, K., ... Mond, J. (2017) Disentangling body image: The relative associations of overvaluation, dissatisfaction, and preoccupation with psychological distress and eating disorder behaviors in male and female adolescents. International Journal of Eating Disorders, 50, 118-126. https://doi.org/10.1002/eat.22592

Mitchison, D., Hay, P., Slewa-Younan, S., \& Mond, J. (2012). Time trends in population prevalence of eating disorder behaviors and their relationship to quality of life. PLoS One, 7, 1-7. https://doi.org/10.1371/journal.pone.0048450

Mitchison, D., Mond, .J, Slewa-Younan, S., \& Hay, P. (2013). Sex differences in health-related quality of life impairment associated with eating disorder features: A general population study. International Journal of Eating Disorders, 46, 375-380. https://doi.org/10.1002/eat.22097

Mitchison, D., Touyz S., González-Chica, D. A., Stocks, N., \& Hay, P. (2017). How abnormal is binge eating? 18-Year time trends in population prevalence and burden. Acta Psychiatrica Scandinavica, 136, 147-155. https://doi.org/10.1111/acps.12735

Mond, J. M., \& Hay, P. (2007) Functional impairment associated with bulimic behaviors in a community sample of men and women. International Journal of Eating Disorders, 40, 391-398. https://doi.org/10.1002/eat.20380

Mond, J. M., Hay, P. J., Rodgers, B., \& Owen, C. (2007). Recurrent binge eating with and without the "undue influence of weight or shape on self-evaluation": implications for the diagnosis of binge eating disorder. Behaviour Research and Therapy, 45, 929-938.

https://doi.org/10.1016/j.brat.2006.08.011

Müller-Nordhorn, J., Roll, S., \& Willich, S. N. (2004). Comparison of the short form (SF)-12 health status instrument with the SF-36 in patients with coronary heart disease. Heart, 90, 523-527. https://doi.org/10.1136/hrt.2003.013995

Rodgers, R.F., McLean, S.A., Marques, M., Dunstan, C.J., \& Paxton, S.J. (2016). Trajectories of Body Dissatisfaction and Dietary Restriction in Early Adolescent Girls: A Latent Class Growth Analysis. Journal of Youth and Adolescence, 45, 1664-1677. https://doi.org/10.1007/s10964-0150356-3

Sonneville, K.R., Grilo, C.M., Richmond, T.K., Thurston, I.B., Jernigan, M., Gianini L., \& Field, A.E. (2015). Prospective association between overvaluation of weight and binge eating among overweight adolescent girls. Journal of Adolescent Health, 56, 25-29.

https://doi.org/10.1016/j.jadohealth.2014.08.017 
Steinglass, J. E., \& Devlin, M. J. (2017). Finding the disorder in binge eating disorder. Acta Psychiatrica Scandinavica, 136, 145-146. https://doi.org/10.1111/acps.12766

Taylor, A., Dal Grande, E., \& Wilson, D. (2006). The South Australian health omnibus survey 15 years on: has public health benefited? Public Health Bulletin South Australia, 3, 30-32.

Ware, J., Kosinski, M., \& Keller, S. (1994). SF-36 Physical and Mental Health Summary Scales: A User's Manual. Boston, MA: The Health Institute.

Ware, J., Kosinski, M., \& Keller, S. (1996). A 12-Item Short-Form Health Survey: construction of scales and preliminary tests of reliability and validity. Medical care, 34, 220-233.

O'Connor, P. J. (1990). Normative data: their definition, interpretation, and importance for primary care physicians. Family Medicine, 22, 307-311.

Onis, M., Onyango, A. W., Borghi, E., Siyam, A., Nishida, C., \& Siekmann, J. (2007).

Development of a WHO growth reference for school-aged children and adolescents. Bulletin of the World Health Organization, 85, 660-667. https://doi.org/10.2471/BLT.07.043497

World Health Organization (1998). Obesity: preventing and managing the global epidemic,

Geneva: World Health Organization. 
Table 1. Sociodemographic variables and BMI from adolescents and adults, Australia, in 2005, 2008/9 and 2015/6.

\begin{tabular}{lcccc}
\hline & 2005 survey & 2008/9 survey & 2015/6 survey & p value \\
\hline Age (years) (mean, SD) & $45.1 \pm 18.8$ & $45.6 \pm 18.9$ & $46.9 \pm 19.4$ & $<.001^{\mathrm{a}}$ \\
BMI (mean, SD) & $26.0 \pm 5.3$ & $26.5 \pm 5.4$ & $27.0 \pm 5.8$ & $<.001^{\mathrm{a}}$ \\
& & & \\
Gender (\%) & & & \\
$\quad$ Male & $1494(49.0)$ & $2960(49.0)$ & $2976(49.2)$ & $0.980^{\mathrm{b}}$ \\
Female & $1553(51.0)$ & $3081(51.0)$ & $3076(50.8)$ & \\
& & & \\
Highest educational attainment $(n, \%)$ & & & \\
$\quad$ Still at school & $199(6.5)$ & $325(5.4)$ & $236(3.9)$ & \\
Left school & $1255(41.2)$ & $2395(39.7)$ & $2064(34.1)$ & \\
Trade qualification & $418(13.7)$ & $780(12.9)$ & $752(12.4)$ & $<.001^{\mathrm{b}}$ \\
Certificate & $689(22.6)$ & $1385(23.0)$ & $1531(25.3)$ & \\
Bachelor & $486(16.0)$ & $1147(19.0)$ & $1462(24.2)$ & \\
\hline
\end{tabular}

${ }^{a}$ ANOVA test

${ }^{b}$ Pearson $\chi^{2}$ test

$\mathrm{SD}=$ standard deviation

Moderate overvaluation

$n(\%)$ $551(18.1)$
95\%
Marked overvaluation

$$
n(\%)
$$

$227(7.5)$
OR $†$
Extreme overvaluation

$n(\%) \quad$ OR $\dagger \quad 95 \%$ CI

OR $†$

95\% CI
$2005(N=3047)$

$227(7.5)$

95\%
$95(3.1)$ 


\begin{tabular}{llllllllll}
$\mathbf{2 0 0 8} / 9(\boldsymbol{N}=\mathbf{6 0 4 1})$ & $2180(36.4)$ & 2.77 & $2.48,3.10$ & $1166(19.4)$ & 3.20 & $2.74,3.74$ & $508(8.5)$ & 2.91 & $2.32,3.65$ \\
$\mathbf{2 0 1 5} / \mathbf{6}(\boldsymbol{N}=\mathbf{6 0 5 2})$ & $2417(40.0)$ & 3.27 & $2.92,3.65$ & $1429(23.7)$ & 4.20 & $3.60,4.90$ & $557(9.2)$ & 3.06 & $2.44,3.84$ \\
\hline
\end{tabular}

Table 2.

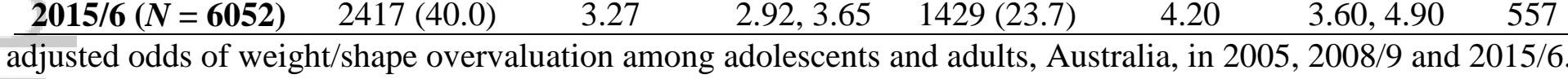

$\mathrm{OR}=$ odds ratio. $\dagger$ ORs are relative to the likelihood of scoring $<4,<5$, or $<6$ on overvaluation in 2005 and are adjusted for gender, age, body mass index, and educational attainment.

Table 3. Number of days out of role (DoR) reported by adolescents and adults with or without weight/shape overvaluation, Australia, in 2005,2009 and 2016.

\begin{tabular}{|c|c|c|c|c|c|c|c|c|c|c|}
\hline 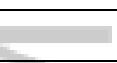 & & $\mathrm{OV} \geq 4$ & OV $<4$ & & $\mathrm{OV} \geq 5$ & $\mathrm{OV}<5$ & & $\mathrm{OV}=6$ & OV $<6$ & \\
\hline 2 & & $\begin{array}{r}\lambda \\
\text { med }\end{array}$ & $\begin{array}{l}D) \\
(I Q R)\end{array}$ & $z(p)$ & $\begin{array}{r}M \\
\text { medi }\end{array}$ & IQR) & $z(p)$ & $\begin{array}{r}M \\
\text { medi }\end{array}$ & (QR) & $z(p)$ \\
\hline 2005 & & $\begin{array}{c}2.95(6.52) \\
0(0-3)\end{array}$ & $\begin{array}{c}1.59(5.22) \\
0(0-0)\end{array}$ & $-7.89(<.001)$ & $\begin{array}{c}3.93(7.26) \\
0(0-4)\end{array}$ & $\begin{array}{c}1.67(5.30) \\
0(0-0)\end{array}$ & $-8.19(<.001)$ & $\begin{array}{c}4.01(7.97) \\
0(0-4)\end{array}$ & $\begin{array}{c}1.77(5.39) \\
0(0-0)\end{array}$ & $-3.76(<.001)$ \\
\hline 2009 & DoR & $\begin{array}{c}2.31(6.43) \\
0(0-0)\end{array}$ & $\begin{array}{c}1.88(5.86) \\
0(0-0)\end{array}$ & $-1.86(.063)$ & $\begin{array}{c}2.73(7.03) \\
0(0-0)\end{array}$ & $\begin{array}{c}1.87(5.81) \\
0(0-0)\end{array}$ & $-2.55(.011)$ & $\begin{array}{c}3.76(8.14) \\
0(0-3)\end{array}$ & $\begin{array}{c}1.91(5.87) \\
0(0-0)\end{array}$ & $-4.55(<.001)$ \\
\hline 2016 & & $\begin{array}{c}1.82(5.31) \\
0(0-0)\end{array}$ & $\begin{array}{c}2.03(5.61) \\
0(0-0)\end{array}$ & $-0.84(.399)$ & $\begin{array}{c}1.84(5.38) \\
0(0-0)\end{array}$ & $\begin{array}{c}1.98(5.52) \\
0(0-0)\end{array}$ & $-1.18(.237)$ & $\begin{array}{c}2.01(5.58) \\
0(0-0)\end{array}$ & $\begin{array}{c}1.93(5.47) \\
0(0-0)\end{array}$ & $-0.88(.379)$ \\
\hline
\end{tabular}

This article is protected by copyright. All rights reserved. 
$\mathrm{OV}=$ overvaluation. $\mathrm{OV} \geq 4$ : moderate overvaluation, $\mathrm{OV} \geq 5$ : marked overvaluation, $\mathrm{OV}=6$ : extreme overvaluation.

Table 4. Mental (MCS) and physical (PCS) health-related quality of life scores reported by adolescents and adults with or without weight/shape overvaluation, Australia, in 2008 and 2015/6.

\begin{tabular}{|c|c|c|c|c|c|c|c|}
\hline 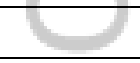 & & $\mathrm{OV} \geq 4$ & $\mathrm{OV}<4$ & $\mathrm{OV} \geq 5$ & $\mathrm{OV}<5$ & $\mathrm{OV}=6$ & $\mathrm{OV}<6$ \\
\hline \multirow{3}{*}{2008} & & $M(\overline{S D})$ & $M(S D)$ & $M(\overline{S D})$ & $M(S D)$ & $M(S D)$ & $M(S D)$ \\
\hline & MCS & $47.37(11.28)$ & $49.70(10.26)^{\mathrm{a}, * * *}$ & $45.28(12.79)$ & $49.74(9.93)^{\mathrm{c},} * * *$ & $43.77(13.87)$ & $49.43(10.13) \mathrm{d}, * * *$ \\
\hline & PCS & $50.67(9.23)$ & $49.72(10.12)$ & $50.38(9.53)$ & $49.98(9.89)$ & $49.32(9.76)$ & $50.14(9.83)$ \\
\hline \multirow[t]{2}{*}{$2015 / 6$} & MCS & $51.86(8.96)$ & $52.95(8.43)^{\mathrm{b}, * *}$ & 52.07 (8.99) & $52.63(8.57)$ & $52.16(9.40)$ & $52.53(8.60)$ \\
\hline & PCS & $49.96(9.59)$ & $48.75(9.97)$ & $49.76(9.98)$ & $49.08(9.77)$ & $48.64(10.93)$ & $49.31(9.71)$ \\
\hline
\end{tabular}

Note. ${ }^{*} \mathrm{p}<0.05, * * \mathrm{p}<0.01, * * * \mathrm{p}<0.001$.

${ }^{\mathrm{a}}$ In 2008, participants with $\mathrm{OV} \geq 4$ scored lower on the MCS than participants with $\mathrm{OV}<4$.

${ }^{\mathrm{b}}$ In 2015/6 participants with OV $\geq 4$ scored lower on the MCS than participants with OV $<4$.

${ }^{\mathrm{c}}$ In 2008, participants with OV $\geq 5$ scored lower on the MCS than participants with OV $<5$.

${ }^{\mathrm{d}}$ In 2008, participants with OV $=6$ scored lower on the MCS than participants with $\mathrm{OV}<6$.

$\mathrm{OV}=$ overvaluation. $\mathrm{OV}>4$ : moderate overvaluation, $\mathrm{OV}>5$ : marked overvaluation, $\mathrm{OV}=6$ : extreme overvaluation.

MCS $=$ mental health component summary; PCS $=$ physical health component summary.

Covariates entered in the regressions included age, gender, body mass index, and educational attainment. 
Table 5. The prevalence and adjusted odds of comorbid obesity and eating disorder behaviors with weight/shape overvaluation in adolescents and adults, Australia, in 2005, 2008/9 and 2015/6.

\begin{tabular}{|c|c|c|c|c|c|c|}
\hline \multirow{2}{*}{$=$} & \multicolumn{2}{|c|}{ Moderate overvaluation } & \multicolumn{2}{|c|}{ Marked overvaluation } & \multicolumn{2}{|c|}{ Extreme overvaluation } \\
\hline & $n(\%)$ & OR $(95 \%$ CI $)$ & $n(\%)$ & OR $(95 \% \mathrm{CI})$ & $n(\%)$ & OR $(95 \% \mathrm{CI})$ \\
\hline \multicolumn{7}{|c|}{ Comorbid Obesity } \\
\hline 2005 & $166(5.5)$ & & $75(2.5)$ & & $36(1.2)$ & \\
\hline 2008-9 & $466(8.0)$ & $1.58(1.32,1.90)$ & $261(4.4)$ & $1.84(1.43,2.38)$ & $144(2.4)$ & $2.12(1.48,3.05)$ \\
\hline 2015-6 & $600(10.2)$ & $2.12(1.78,2.53)$ & $356(6.0)$ & $2.67(2.08,3.42)$ & $147(2.5)$ & $2.27(1.58,3.25)$ \\
\hline \multicolumn{7}{|c|}{ Comorbid OBE } \\
\hline 2005 & $98(3.2)$ & & $52(1.7)$ & & $28(0.9)$ & \\
\hline 2008-9 & $221(3.7)$ & $1.17(0.90,1.50)$ & $144(2.4)$ & $1.35(0.97,1.88)$ & $81(1.3)$ & $1.38(0.88,2.17)$ \\
\hline 2015-6 & $454(7.5)$ & $2.51(1.97,3.18)$ & $289(4.8)$ & $2.73(2.00,3.71)$ & $126(2.1)$ & $1.92(1.25,2.96)$ \\
\hline \multicolumn{7}{|c|}{ Comorbid Strict Dieting/Fasting } \\
\hline 2005 & $79(2.6)$ & & $49(1.6)$ & & $24(0.8)$ & \\
\hline 2008-9 & $170(2.8)$ & $1.25(0.93,1.66)$ & $129(2.1)$ & $1.50(1.05,2.14)$ & $79(1.3)$ & $1.63(1.02,2.61)$ \\
\hline 2015-6 & $204(3.4)$ & $1.44(1.09,1.91)$ & $132(2.2)$ & $1.53(1.07,2.18)$ & $68(1.1)$ & $1.30(0.80,2.10)$ \\
\hline \multicolumn{7}{|c|}{ Comorbid Purging } \\
\hline 2005 & $18(0.6)$ & & $10(0.3)$ & & $6(0.2)$ & \\
\hline 2008-9 & $36(0.6)$ & $1.10(0.62,1.94)$ & $26(0.4)$ & $1.36(0.65,2.84)$ & $19(0.3)$ & $1.65(0.65,4.16)$ \\
\hline $2015-6$ & $19(0.3)$ & $0.50(0.26,0.99)$ & $19(0.3)$ & $0.84(0.38,1.87)$ & $13(0.2)$ & $1.03(0.38,2.81)$ \\
\hline
\end{tabular}

Note. ORs are relative to the likelihood of the event occurring in 2005.

Covariates entered in the regressions included age, gender, body mass index (except in analyses with obesity as the outcome), and educational attainment. 


\section{University Library}

\section{- M M N E R VA A gateway to Melbourne's research publications}

Minerva Access is the Institutional Repository of The University of Melbourne

Author/s:

Santana, DD;Mitchison, D;Griffiths, S;Appolinario, JC;da Veiga, GV;Touyz, S;Hay, P

Title:

Ten-year time trends in mental and physical health correlates of weight/shape overvaluation

Date:

2019-09-01

Citation:

Santana, D. D., Mitchison, D., Griffiths, S., Appolinario, J. C., da Veiga, G. V., Touyz, S. \& Hay, P. (2019). Ten-year time trends in mental and physical health correlates of weight/ shape overvaluation. EUROPEAN EATING DISORDERS REVIEW, 27 (5), pp.531-540. https:// doi.org/10.1002/erv.2672.

Persistent Link:

http://hdl.handle.net/11343/285634 